\title{
Fine's trilemma and the reality of tensed facts
}

\author{
Roberto Loss \\ robertoloss.com \\ Forthcoming in Thought: A Journal of Philosophy \\ Penultimate draft: please refer to the published version
}

\begin{abstract}
Fine (2005, 2006) has presented a 'trilemma' concerning the tenserealist idea that reality is constituted by tensed facts. According to Fine, there are only three ways out of the trilemma, consisting in what he takes to be the three main families of tense-realism: 'presentism', '(external) relativism', and 'fragmentalism'. Importantly, although Fine characterises tense-realism as the thesis that reality is constituted (at least in part) by tensed facts, he explicitly claims that tense realists are not committed to their fundamental existence. Recently, Correia and Rosenkranz $(2011,2012)$ have claimed that Fine's tripartite map of tense realism is incomplete as it misses a fourth position they call 'dynamic absolutism'. In this paper, I will argue that dynamic absolutists are committed to the irreducible existence of tensed facts and that, for this reason, they face a similar trilemma concerning the notion of fact-content. I will thus conclude that a generalised version of Fine's trilemma, concerning both fact-constitution and fact-content, is indeed inescapable.
\end{abstract}

\section{Fine's trilemma and the reduction of tensed facts}

It appears fair to say that Fine's $(2005,2006)$ novel 'map' of tense realism is one of the most important contributions to the debate on the reality of tense in recent years. According to this map, tense realism is divided into three main families of theories: presentism, (external) relativism, and fragmentalism, which correspond to the negation of the three main theses that Fine argues to be jointly incompatible with tense realism:

Neutrality: No time is privileged, the tensed facts that constitute reality are not oriented towards one time as opposed to another.

Absolutism: The constitution of reality [by means of tensed facts] is an absolute matter, i.e. not relative to a time or other form of temporal standpoint.

Coherence: Reality is not contradictory, it is not constituted by [tensed] facts with incompatible content. (Fine, 2005: 271; my italics)

Fine's characterisation of tense realism in terms of tensed facts may strike one as an undesirable feature of his theory. As a matter of fact, not only is it clearly a controversial issue whether entities like facts exist, but it also seems fair to say that, within the family of fact-like entities, the nature of 'tensed facts' appears to be particularly elusive. However, Fine is quite explicit in taking tensed facts to always be reducible. His favoured way of reduction involves the reality operator 'in reality, it is the case that':

My preference, though this may not be the only option, is to take there to be a primitive sentential operator, call it $\mathbf{R}$, whose intended reading is, 'in reality, it is the case that'. [...] Thus someone who wished to subscribe to the reality of tense 
might well endorse the claim that in reality I am sitting $(\mathbf{R} S)$, while someone who wished to deny the reality of tense would endorse its negation $(\sim \mathbf{R} S)$. (Fine, 2005: 268).

According to Fine, although tense-realists can speak of the existence of the fact that I am sitting now, and say things like 'Reality is constituted by the fact that I am now sitting', they are not committed to the fundamental existence of tensed facts, as they can also acknowledge that no tensed fact really exists, since what is really the case is simply that I am now sitting.

Fine's choice of reducing tensed facts by means of the reality operator corresponds to his distinction between 'mere reality, or how things are, and metaphysical reality, or how things really are' (Fine 2005: 267), which is in turn based on the general idea that 'in a [true] representation of reality, there may be features of the representation that do not faithfully reflect what is represented' (Fine 2005: 267). As Fine himself acknowledges, however, his metaphysical conception of reality is but one of many possible ways in which tense-realists may reduce tensed facts. Although he doesn't explicitly explore other ways of reduction, alternative options don't seem too difficult to come by. For instance, a (slightly) less controversial option may be the one resorting to the notion of grounding. Tense-realists may in fact claim that, although reality is indeed constituted by the tensed fact that I am sitting right now, this tensed fact exists because I am sitting right now (and not vice versa). ${ }^{1}$ In this way, if tense realists also took (i) an entity to be fundamental if and only if its existence is not grounded in anything, ${ }^{2}$ and (ii) claimed that only fundamental entities carry the weight of ontological commitment, ${ }^{3}$ they could both claim that tensed facts exist without having to countenance them in the list of their ontological commitments. Alternatively, tense-realists may adopt a metaphysical framework along the lines of Sider's (2011) and claim that although 'the fact that I am sitting right now exists' is indeed a true statement, its metaphysical semantics - stating its truth-conditions in perfectly joint-carving terms (Sider 2011: 1125) - is simply given in terms of tensed statements (thus acknowledging that 'tense operators carve at the joints', Sider, 2011: 247).

The general idea behind all these possible ways of reduction is that, in order to reduce tensed facts, there must be some truths somehow metaphysically underpinning the truths concerning their existence. Notice that although the specific nature of this kind of underpinning will depend on the specific details of the chosen reductive strategy, a necessary requirement for the reduction of tensed facts appears to be that their 'tensedfacts-free' underpinning should metaphysically entail their existence, at least in the following sense:

\footnotetext{
${ }^{1}$ For an introduction to the notion of grounding see Bliss \& Trogdon (2014) and Correia \& Schnieder (2012). On the 'operational view' on grounding see Correia (2010), Schnieder (2011), Correia \& Schnieder (2012), and Fine (2012).

${ }^{2}$ Grounding-theorists can say, for instance, that (i) something is fundamental if and only if it is an ontologically independent entity and (ii) something is ontologically independent if and only if the fact that it exists is not grounded in anything (see Correia, 2005 and Schnieder, 2006).

${ }^{3}$ On a similar view on ontological commitment (although assuming a predicational stance on grounding) see Schaffer (2015).
} 
(N) For every truth $\mathrm{P}$ concerning the existence of tensed facts, if $\mathrm{P}$ reduces (according to the relevant notion of 'reduction' in play) to $\mathrm{Q}$, then it is necessarily the case that: if $\mathrm{P}$ is true, then $\mathrm{Q}$ is true.

In fact, not only $(\mathrm{N})$ strikes one as quite plausible on its own, but it also appears to be widely endorsed in the literature. $(\mathrm{N})$ corresponds to the 'Entailment Principle' (Rosen 2010: 118) in the literature on grounding, while Sider appears to endorse an even stronger, biconditional counterpart of (N) (Sider 2013: 767).

\section{A way out: dynamic absolutism}

It seems fair to say that many theorists may warmly welcome the possibility to safely navigate the waters of tense realism avoiding both the Scylla of presentism and the Charybdis of Fine's non-standard forms of realism about tense. As commonsensical as it is sometimes claimed to be in the literature, presentism is a theory that is saddled by well-known problems. ${ }^{4}$ At the same time, Fine's 'non-standard' form of tense realism (that is, fragmentalism and relativism) may still strike many as too metaphysically extravagant to be taken as live options. ${ }^{5}$

A way out of 'Fine's trilemma' (Correia and Rosenkranz 2011: 95) is precisely what Correia and Rosenkranz's $(2011,2012)$ recent work on tense realism promises. In fact, according to Correia and Rosenkranz (henceforth 'C\&R'), Fine's map of tense realism misses a fourth position, which they label 'dynamic absolutism'. ${ }^{6}$ Dynamic absolutism is presented by $C \& R(2011,2012)$ as a theory characterised by two claims:

\section{Dynamic Absolutism:}

(i) facts are 'eternal' (so that Eternalism is true):

(ii) and yet their content changes over time (so that Fixed Content is false)

Eternalism: For every time $t$, and every fact $f, f$ constitutes reality at $t$ if, and only if, for every time $u$, it constitutes reality at $u{ }^{7}$

Fixed Content: If at time $t$, tensed fact $f$ both constitutes reality and is the fact that $p$, then for every time $u$, if $f$ constitutes reality at $u$, then at $u, f$ is the fact that $p .8$

\footnotetext{
${ }^{4}$ See Sider (2001: chapter 2) for a general presentation of presentism's problems. It may be argued that the kind of theory that Fine labels 'presentism' doesn't only include what is commonly known in the literature as 'presentism,' but also other classical A-theories of time, like the growing-block theory and the movingspotlight theory (see on this Loss 2017). But, as Fine himself has argued, there are other problems seemingly surrounding any presentist theory in Fine's sense, as the apparent inability to provide an adequate account of the passage of time (Fine 2005: 284-307).

${ }^{5}$ See, for instance, Deng (2012: 28-9).

${ }^{6} \mathrm{C} \& \mathrm{R}$ (2011) refer to dynamic absolutism as 'Absolutist Anti-Recurrentism'.

${ }^{7}$ Notice that C\&R (2011) name this thesis 'Sempiternalism' (2011: 44).

${ }^{8}$ C\&R (2012: 310). See also C\&R (2011: 58).

${ }^{9}$ The reason why C\&R take dynamic absolutism to be an absolutist form of tense realism lies in the fact that they explicitly define absolutism as both entailing eternalism and being entailed by it (C\&R, 2011: 56; 2012: 309). As Fine (2005: 271-2) himself acknowledges, however, absolutists and relativists shouldn't be seen as disagreeing about whether the notion of constitution is absolute or relative, but instead about which notion is explanatorily prior. Therefore, both Fine's relativists and Fine's absolutists appear to be in position to endorse eternalism, which is, thus, a thesis that is in itself neutral with respect to the absolutism/relativism
} 
Dynamic absolutists agree with Fine that tense realists should take reality to be 'reasonably variegated over time':

Variegation: any reasonable view of how temporal reality might be constituted should allow for its being reasonably variegated over time; and presumably it will then be constituted by incompatible facts, i.e. by facts with incompatible contents. (Fine, 2005: 272)

However, they also claim - contra Fine - that they can endorse Variegation without rejecting Neutrality, Absolutism or Coherence. Their argument, in a nutshell, is the following. From Variegation it follows that there two times $t_{1}$ and $t_{2}$ and two incompatible propositions $p$ and $q$ such that:

(1) There is a fact $f$ such that $f$ constitutes reality at $t_{1}$ and is at $t_{1}$ the fact that $p$

(2) There is a fact $g$ such that $g$ constitutes reality at $t_{2}$ and is at $t_{2}$ the fact that $q$

However, without Fixed Content it is not possible (even assuming Neutrality, Absolutism, Coherence and Eternalism) to conclude from (1) and (2) that there is a time $t$ such that $f$ and $g$ constitute reality at $t$ and have, at $t$, the incompatible contents $p$ and $q$. In fact, if facts can change their content over time, either $f$ or $g$ can simply have at $t$ a different content than the one they have at $t_{1}$ and $t_{2}$ (respectively), thus not contradicting Neutrality, Absolutism or Coherence. ${ }^{10}$

\section{Irreducible facts in an ageing universe}

Although Fine isn't explicit on this point, it seems clear that the operator 'In reality, it is the case that' is an absolutist reality operator and that, most plausibly, Fine's (external) relativists should resort to a temporally relativized reality operator along the lines of 'In reality at time $t$, it is the case that'. ${ }^{11}$ Therefore, relativists who don't wish to accept tensed facts in their fundamental ontology appear to have an easy way to reduce (1) and (2) by means of a temporally relativized reality operator, as they can consistently claim that (1) and (2) reduce to

(3) In reality-at- $t_{1}$, it is the case that $p$

(4) In reality-at- $t_{2}$, it is the case that $q$

\footnotetext{
distinction. For instance, absolutists may define the relative notion of constitution by saying that, for every time $t$, if a fact $f$ obtains absolutely, then (in virtue of obtaining absolutely) it also obtains at $t$-from which it follows that every fact obtains both absolutely and eternally. In the same way, relativists may take a fact to obtain absolutely just in case it obtains at every time (that is, eternally). Therefore, if they also endorse eternalism, they can also claim that every fact (in virtue of obtaining at every time) also obtains absolutely. It follows, thus, that dynamic absolutism as defined by $\mathrm{C} \& \mathrm{R}$, is a theory that is actually compatible with both absolutism and relativism.

${ }^{10}$ See, in particular, C\&R (2011: 95-101; 2012: 309-11).

${ }^{11}$ Here and in what follows I am drawing on the analysis of Fine's argument I present and defend in Loss (2017).
} 
Absolutists take facts to constitute reality with respect to a temporal standpoint in virtue of constituting reality absolutely. ${ }^{12}$ However, dynamic absolutists cannot account for (1) and (2) simply as follows:

(5) In reality, it is the case that $p$

(6) In reality, it is the case that $q$

In fact, since $p$ and $q$ are incompatible propositions, dynamic absolutists would be saying in this case not only that reality is constituted simpliciter by incompatible facts but also that this kind of 'incoherence' is not ironed out at a more fundamental level of reality ( $p$ and $q$ are in fact both really the case). This, however, appears to be precisely the essence of the fragmentalist position:

One naturally assumes that in a correct account of reality all apparent contradictions will be ironed out. If something is both hot and cold, it must be because one part is hot and the other cold, or because it is hot and cold at different times, or because being hot is somehow compatible with being cold. But on the present view, this fundamental assumption is given up. It is taken to lie in the character of reality that certain apparently contradictory aspects of it cannot be explained away. Reality may be irredeemably incoherent (Fine 2005: 280-81)

Consider, furthermore, the plausible constraint of 'No Collapse' that Fine (2005) imposes on tense realism:

No Collapse: 'in explaining one notion of composition in terms of another, the realist's position should not collapse into an anti-realist position. In other words, reality's being composed of certain tensed facts should not be taken simply to be a matter, according to the explanation, of its being composed of tenseless facts. Suppose, for example, that the realist were to provide the following explanation of relative composition; for reality to be composed of a tensed fact $f$ at a time $t$ is for it to be composed of the fact $f$-at- $t$. This would then be clearly in violation of No Collapse; and it is also clear, when there is a violation, that the realist's position is realist in name only' (Fine 2005: 273)

In order to dispense with the existence of tensed facts without collapsing into a fragmentalist position, dynamic absolutists must then claim that there are two compatible propositions $r$ and $s$ such that that (1) and (2) can be reformulated by means of the reality operator as follows:

(7) In reality, it is the case that $r$

(8) In reality, it is the case that $s$

However, on the one hand, as we saw in section 1.2, principle $(\mathrm{N})$ requires $(7)$ and $(8)$ to entail that $p$ is the case at $t_{1}$ and $q$ is the case at $t_{2}$. On the other hand, No Collapse clearly excludes that (7) and (8) can be simply reformulated as:

\footnotetext{
${ }^{12}$ See footnote 9.
} 
(9) In reality, it is the case that $p$-at- $t_{1}$

(10) In reality, it is the case that $q$-at- $t_{2}$

The problem appears to generalise: what pair of propositions could be (i) compatible with each other, (ii) in compliance with No Collapse, and (iii) such as to entail that $p$-at$t_{1}$ and that $q$-at- $t_{2}$ (respectively)?

One way to avoid collapsing dynamic absolutism into fragmentalism while at the same time complying with $(\mathrm{N})$ is that of prefixing the relevant reality statements with some temporal operators. For instance, supposing that it is now $t_{2}$ and that $t_{1}$ is $n$ timeunits in the past, dynamic absolutists could claim the following:

(11) It was the case $n$ time-units that, in reality, it is the case that $p$

(12) It is now the case that, in reality, it is the case that $q$

Clearly, in order not to fall back into a form of fragmentalism, (11) must not entail (5). ${ }^{13}$ However, the idea that reality claims can be 'non-factively' prefixed by temporal operators - so that, for instance, 'it was the case that, in reality, $p$ ' can be true without $p$ being true - seems to be a characterising feature of Fine's presentism. In fact, when he formulates presentism in terms of fact-constitution he explicitly takes it to be the view according to which

'there is an absolute notion of constitution, but it is tensed' (Fine 2005: 2767 ; my italics). ${ }^{14}$

Therefore, if presentism is instead characterised by means of a primitive notion of reality, then it seems natural to take it as the claim that

there is an absolute, primitive notion of reality, but it is tensed,

so that (11) can be true without (5) being true. It follows, thus, that also the strategy represented by (11) and (12) is unavailable to dynamic absolutists.

Notice that what has been said about the reduction of tensed facts by means of Fine's reality operator appears to also apply to other possible reductive strategies (see above: section 1). According to the grounding approach, for instance, a reduction of tensed facts would have to have the form of statements like:

(13) There is a fact $f$ such that $f$ constitutes reality at $t_{1}$ and is at $t_{1}$ the fact that $p$ because $\mathrm{A}$

(14) There is a fact $g$ such that $g$ constitutes reality at $t_{2}$ and is at $t_{2}$ the fact that $q$ because $\mathrm{B}$

where A and B are tensed-facts-free sentences. Similarly, for the metaphysical semantics approach, a reduction of (1) and (2) should be given by statements having the form

\footnotetext{
${ }^{13}$ Since the operator 'it is now the case that' is most plausibly taken to be factive, (12) entails (6).

${ }^{14}$ On this way to characterise Fine's presentism see also Loss (2017).
} 
(1) is true if and only if C

(2) is true if and only if D

where $\mathrm{C}$ and $\mathrm{D}$ are tensed-facts-free sentences cast in perfectly joint-carving terms. Even in these cases, however, the order appears to be a tall one, as both [A and B], and [C and D] should be (i) be compatible with each other (in order to avoid fragmentalism), (ii) not collapse into an anti-realist position (to comply with No Collapse), and yet (iii) entail that $p$ is the case at $t_{1}$ and $q$ is the case at $t_{2}$ (by principle $\mathrm{N}$; see above: section 1), (iv) without being tensed (in order to avoid presentism).

\section{A generalised version of Fine's trilemma}

In the previous section I have argued that dynamic absolutists must take tensed facts to be irreducible. This also appears to entail that dynamic absolutists cannot endorse at the same time the following counterparts of Neutrality, Absolutism, and Coherence concerning the notion of fact-content:

Content Neutrality: The content of tensed facts is not oriented towards one time as opposed to another.

Content Absolutism: The content of tensed facts is an absolute matter, i.e. not relative to a time or other form of temporal standpoint.

Content Coherence: Reality is not contradictory; there is no tensed fact having incompatible contents.

Suppose, in fact, that a fact $f$ is at $t_{1}$ the fact that $p$ and at $t_{2}$ the fact that $q$, where $p$ and $q$ are incompatible contents. By Content Absolutism, $f$ is simpliciter both the fact that $p$ and the fact that $q$. This, however, contradicts Content Coherence (so that the situation is parallel to the case of (5) and (6); see above). However, the contradiction cannot be solved by saying, for instance, that $f$ is the fact that $p$ and will be the fact that $q$, since that would contradict Content Neutrality (see (11) and (12)). At the same time, dynamic absolutists cannot say that the two contents $f$ possesses simpliciter are anything along the lines of $\left\langle p\right.$-at- $\left.t_{1}\right\rangle$ and $\left\langle q\right.$-at- $\left.t_{2}\right\rangle$, as that would clearly contradict No Collapse (see above).

It follows, thus, that dynamic absolutists must endorse either content-presentism ( $f$ is the fact that $p$ and will be the fact that $q$ ), content-relativism ( $f$ is at $t_{1}$ the fact that $p$ and at $t_{2}$ the fact that $q$, where the relative notion of fact-content is in this case thought of as irreducible to an absolute one) ${ }^{15}$ or content-fragmentalism ( $f$ is both the fact that $p$ and the fact that $q) .{ }^{16}$ In turn, this appears to have two main consequences.

First, consider the content-presentist version of dynamic absolutism. According to it, there are a bunch of tensed facts that exist simpliciter and that although they are now the fact that $p, q$, r et cetera, they were and will be facts with different content. $\mathrm{C} \& \mathrm{R}$

\footnotetext{
${ }^{15}$ See footnote 9 on the definition of absolutism and relativism in terms of explanatory priority.

${ }^{16}$ In this case, content-fragmentalists could say (loosely following Loss 2017) that although $f$ is the fact that $p$ and $f$ is the fact that $q$, it is not the case that $f$ is the fact that $p$ and $q$ (so that $p$ and $q$ belong in this case to two 'fragments of content' not 'cohering' into a single content).
} 
(2011: 103-5, 2012: 314-6) explicitly endorse a view according to which tensed facts (like the fact that Sam will be sitting three days hence) are entities that are (somehow) composed by one of more entities (like Sam) and a 'predicable'. In turn, they take 'predicables' to be tensed properties (like 'sitting three days hence') which are associated with both a 'proto-property' (like 'sitting') and a 'tense-aspect' (like 'three days from the present'). If we assume this theory of tensed facts, it seems that what a contentpresentist dynamic absolutist should say in the case of Sam's sitting is that there is an entity (Sam) that exists eternally and is such that the tense-aspect of the tensed properties it instantiates constantly changes ('three days hence', 'two days hence', 'now', 'one day ago', et cetera), so that also the fact that Sam was/is/will-be sitting $n$ days ago/now/n days hence is eternal. However, this strikes one as just being a permanentist (Williamson 2013) and Lucretian (Bigelow 1996) form of presentism, according to which entities never begin or cease to exist and the only change there is in reality concerns what tensed properties they instantiate. Similarly, although it is not obvious how the story about tensed facts would go in the case of content-relativism and content-fragmentalism, it is difficult to see how dynamic absolutists could in that case avoid the collapse of their position into a plain form of relativism and fragmentalism, respectively. The trilemma about content seems thus to reveal a certain instability at the core of dynamic absolutism.

Second, in formulating Neutrality and Absolutism, Fine only employs the notion of fact-constitution. Presumably this is due to the fact that he is implicitly assuming Fixed Content and thus taking facts not to be capable of changing their content. However, it appears fair to say that as long as reality is thought of as being (somehow) constituted by facts that (somehow) possess a certain content, both the notion of factconstitution and the notion of fact-content should take the centre-stage of one's conception of reality (which appears to be confirmed by the fact that Coherence is originally formulated by Fine in terms of both fact-constitution and fact-content). Therefore, once Fixed Content is rejected, it appears to be faithful to at least to the spirit of Fine's original trilemma to generalise Neutrality, Absolutism and Coherence accordingly:

General Neutrality: No time is privileged: neither the tensed facts that constitute reality nor their content are oriented towards one time as opposed to another.

General Absolutism: Both the constitution of reality by means of tensed facts and their content is an absolute matter, i.e. not relative to a time or other form of temporal standpoint.

General Coherence: Reality is not contradictory, it is not constituted by one or more tensed facts with incompatible content.

Therefore, if what has been said in this paper is on the right track, it follows that at least this generalised version of Fine's trilemma appears to be indeed inescapable and, therefore, that no form of tense realism can consistently embrace a general conception 
of reality - and, thus, of both facts and their contents - that is at the same time neutral, absolutist and coherent. ${ }^{17}$

\section{References}

Bigelow, J. 1996. Presentism and properties. Philosophical Perspectives, 10, 35-52.

Bliss, R. \& Trogdon, K. 2014. Metaphysical Grounding. Stanford Encyclopedia of Philosophy. (Winter 2014 Edition), E. N. Zalta (ed.), URL= <http://plato.stanford.edu/archives/win2014/entries/grounding/>.

Correia, F. 2005. Existential Dependence and Cognate Notions. München: Philosophia Verlag.

Correia, F., \& Rosenkranz, S. 2011. As time goes by. Eternal Facts in an Ageing Universe.

Correia, F., \& Rosenkranz, S. 2012. Eternal facts in an ageing universe. Australasian Journal of Philosophy, 90(2): 307-320.

Correia, F. and B. Schnieder (eds.) 2012. Introduction. In Correia, F. and B. Schnieder (eds.) 2012a. Metaphysical Grounding: Understanding the Structure of Reality. Cambridge: Cambridge University Press.

Fine, K. 2005. Tense and Reality, in his Modality and Tense, Oxford: Oxford University Press: 261-320.

Fine, K. 2006. The Reality of Tense, Synthese 150(3): 399-414.

Fine, K. 2012. Guide to ground. In: Correia, F. and B. Schnieder (eds.) 2012a. Metaphysical Grounding: Understanding the Structure of Reality. Cambridge: Cambridge University Press.

Loss, R. 2017. Fine's McTaggart: Reloaded. Manuscrito: Revista Internacional de Filosofía. 40(1): 209-39

Rosen, G. 2010. Metaphysical Dependence: Grounding and Reduction. In Bob Hale \& Aviv Hoffmann (eds.), Modality: Metaphysics, Logic, and Epistemology. Oxford University Press: 109-36.

Schaffer, J. 2015. What Not to Multiply Without Necessity. Australasian Journal of Philosophy 93 (4):644-64.

Schnieder, B. 2006. A Certain Kind of Trinity: Dependence, Substance, Explanation. Philosophical Studies 129(2): 393-419.

Schnieder, B. 2011. A logic for 'because'. Review of Symbolic Logic 4 (3):445-465.

Sider, T. 2001. Four-Dimensionalism: An Ontology of Persistence and Time. Oxford University Press.

Sider, T. 2011. Writing the Book of the World. Oxford University Press.

Sider, T. 2013. Symposium on Writing the Book of the World. Analysis 73 (4):751-70. Williamson, T. 2013. Modal Logic as Metaphysics. Oxford: Oxford University Press.

\footnotetext{
${ }^{17}$ Many thanks to two anonymous referees for this journal for useful comments. I am very grateful to Sven Rosenkranz for discussing earlier drafts of this paper with me.
} 